\title{
The implications of fossil fuel supply constraints on climate change
}

\section{projections: A supply-side analysis}

\author{
Jianliang Wang ${ }^{1}$, Lianyong Feng ${ }^{1}$, Xu Tang ${ }^{1}$, Yongmei Bentley ${ }^{2}$, Mikael Höök ${ }^{3}$ \\ ${ }^{1}$ China University of Petroleum (Beijing), School of Business Administration, 102249, 18 Fuxue \\ Road, Changping District, Beijing, China. Email: fenglyenergy@ 163.com(Feng L.Y.), \\ tangxu2001@163.com(Tang X.)
}

2 University of Bedfordshire, Business School, Luton LU1 3JU, UK. Email: Yongmei.Bentley@beds.ac.uk (Bentley Y.)

${ }^{3}$ Uppsala University, Global Energy Systems, Department of Earth Sciences, 752 36, Villavägen 16, Sweden. Email: mikael.hook@geo.uu.se (Höök M.)

Corresponding author: Jianliang Wang (wangjianliang305@ 163.com).

Abstract: Climate projections are based on emission scenarios. The emission scenarios used by the IPCC and by mainstream climate scientists are largely derived from the predicted demand for fossil fuels, and in our view take insufficient consideration of the constrained emissions that are likely due to the depletion of these fuels. This paper, by contrast, takes a supply-side view of $\mathrm{CO}_{2}$ emission, and generates two supply-driven emission scenarios based on a comprehensive investigation of likely long-term pathways of fossil fuel production drawn from peer-reviewed literature published since 2000. The potential rapid increases in the supply of the non-conventional fossil fuels are also investigated. Climate projections calculated in this paper indicate that the future atmospheric $\mathrm{CO}_{2}$ concentration will not exceed $610 \mathrm{ppm}$ in this century; and that the increase in global surface temperature will be lower than $2.6^{\circ} \mathrm{C}$ compared to pre-industrial level even if there is a significant increase in the production of non-conventional fossil fuels. Our results indicate therefore that the IPCC's 
climate projections overestimate the upper-bound of climate change. Furthermore, this paper shows that different production pathways of fossil fuels use, and different climate models, are the two main reasons for the significant differences in current literature on the topic.

Key words: Supply Constraints; Emission Scenarios; Climate Projections; Fossil Fuel Resources

\section{Introduction and Research Background}

Climate change has been seen as perhaps the biggest environmental threat to the future development of human society (Alley et al., 2003), and anthropogenic greenhouse gas (GHG) emissions, especially $\mathrm{CO}_{2}$ emissions mainly due to the usage of fossil fuels, have been considered as the dominant cause of the observed change in the global climate to-date (IPCC, 2007, 2013). The results of climate projections are crucial for international climate negotiations. Therefore, as the basic input and a major uncertainty in climate projections (Stott and Kettleborough, 2002; Garrett, 2011), anthropogenic emissions should be given substantial research attention (Webster et al., 2002).

Until recently, emissions scenarios from the Special Report on Emissions Scenarios (SRES) of the Intergovernmental Panel on Climate Change (IPCC) (IPCC, 2000) are most commonly used by the IPCC itself, and by much other scientific literature in order to analyze relevant impacts on natural, social, and economic systems, and to recommend policies or measures to cope with climate change effects (IPCC, 2001, 2007; Stott and Kettleborough, 2002; Arnell et al., 2004, 2013). However, the anthropogenic future emissions resulting from energy usage in these scenarios were all largely derived from a demand-side analysis (Brecha, 2008; Vernon et al., 2011; York, 2012; Höök et al., 2013). In that analysis fossil fuel resources were assumed to be abundant, especially if non-conventional fossil fuel resources were included (Rogner, 1997). Moreover, it was assumed that these resources could be 
extracted at the required flow rate to meet demand due to the improving technical and economic conditions. Thus the future usage of fossil fuels largely only depended on demand, which in turn was set by the assumed future levels of socio-economic development. This 'demand-driven' approach to setting emission scenarios has been supported by most economists, and as mentioned, was adopted by IPCC in developing the emissions scenarios contained in SRES.

In 2009, a set of new emission scenarios (the representative concentration pathways or RCPs) were developed and released, and used in the Fifth Assessment Report (AR5) of Climate Change by the IPCC (Moss et al., 2010; Rogelj et al., 2012). However, these new emission scenarios are still fundamentally demand-driven, and are based on similar socioeconomic models as those used to develop the SRES scenarios (Ward et al., 2012). Therefore, both SRES and RCPs include some extremely high emissions scenarios, such as A1FI in SRES, and RCP8.5 in the RCPs. Furthermore, all of the scenarios in SRES and RCPs are considered equally plausible, since no probabilities or likelihoods are given to these (IPCC, 2000; Moss et al., 2010; Höök et al., 2013).

In this paper we look at the issue of $\mathrm{CO}_{2}$ emissions from the supply side, and hence from the need to recognize that fossil fuels, the main energy sources and dominant contributor to current and future anthropogenic $\mathrm{CO}_{2}$ emissions, are finite. This is mainly reflected in two aspects: one is in geology, which means the total volumes existing in the earth are finite (i.e., the total resources); the other is in technology and economics, which means the recoverable volumes from the total volumes, are also limited (i.e., the recoverable resources). Generally, the volumes of total resources are much larger than the volumes of recoverable resources. However, compared to the total resources, the recoverable resources are the more important for future production, since the production rate of any fossil fuel is influenced not only by geological factors, but also by technical and economic factors. In the IPCC's SRES and RCPs, 
the total resources are chosen as the base for analyzing future supply (IPCC, 2000). Moreover, even if the recoverable resources are large this does not automatically permit their production to be large. This is because empirical evidence shows that the production of fossil resources in most regions reaches a peak even when up to more than a half of the recoverable resources still remain (Brandt, 2007). As a result, the production curves of fossil fuels should generally be modeled as rising to a peak and then decreasing.

An early peak study of fossil fuel production was that by Hubbert (Hubbert, 1949). Since then much scientific literature has been written analyzing the possible peaks in exploitation of global or regional fossil fuels and their possible impacts on the development of the economy and human society (see, for example, Nel and Cooper, 2009; Nel and van Zyl, 2010). Today the concept of peak fossil fuel production is generally widely accepted (Zhao et al., 2009; de Almeida and Silva, 2011; Bentley and Bentley, 2015), and an increasing number of scientific and commercial forecasts have shown that the world will experience a near-term production peak (or at least, plateau) of conventional fossil fuel production, and especially of the production of convention oil and conventional gas (Campbell and Laherrere, 1998; Kerr, 2011; Heinberg and Fridley, 2010; Murray and King, 2012). Moreover, the International Energy Agency (IEA), one of the world's main energy forecasting organizations, has been steadily reducing its forecast global production levels for conventional fossil hydrocarbons (i.e., oil \& gas) in its annual flagship reports, the World Energy Outlooks (WEOs) (Miller, 2011). The IEA first mentioned the issue of peak oil in its WEO 1998, and later in all WEOs published since 2008; and also indicated that the global production of conventional crude oil (less natural gas liquids, NGLs) had possibly peaked in 2006 (IEA, 2008).

The peak in fossil fuel production has been seen as an extremely important issue for humankind (Krumdieck et al., 2010), and as mentioned above the coming of peak fossil fuels may have significant influence on climate change due to the close relationship between usage 
of fossil fuels and the anthropogenic $\mathrm{CO}_{2}$ emissions (Newbery, 2011; Friedrichs, 2011). Hence, in our view, supply-side analysis is needed to examine the likely upper-bound usage of fossil fuels, and hence related emissions, even though we recognize that technological progress can mitigate such constraints to some extent (Meadows and Randers, 2004).

A number of studies have already paid attention to possible supply-driven emission scenarios, and hence their impacts on climate projections. These include Grubb (2001), Doose (2004), Brecha (2008), Kharecha and Hansen (2008), Nel and Cooper (2009), Tans (2009), Chiari and Zecca (2011), Ward et al. (2011, 2012) and Höök et al. (2013). However, many of these studies use their own, and often rather simple, analyses of future fossil fuel production; and moreover the production in some of these analyses covers only conventional fossil fuels, and not all fossil fuels, thus giving insufficient consideration of the likely increasing production of the non-conventional fossil fuels (Brecha, 2008; Kharecha and Hansen, 2008; Nel and Cooper, 2009; Chiari and Zecca, 2011). As a result, such studies are likely to give a less than convincing conclusion (Kharecha and Hansen, 2008). Furthermore, the significant differences among the se current supply-side studies call for a comprehensive analysis of the reasons for these differences. Note also that such supply-side analyses, and their related emission scenarios, are still largely excluded by many economists and climate scientists in climate change analyses (Ward et al., 2012).

The aim of this paper, therefore, is to present a comprehensive analysis in order to understand the impacts of supply constraints of all fossil fuels (oil, gas and coal, and both conventional and non-conventional) on future climate change.

\section{Research ideas and methodology}

To design supply-driven emission scenarios, we need to know the future usage of fossil fuels, and where, as this is an supply-side analysis, this usage depends on predicted supply (i.e., 
production) rather than on simply predicted demand (based on the predicted status of the world economy). To better understand the future production trends of fossil fuels, and as opposed to most current studies in this area, we will not try to forecast these trends ourselves, but to present firstly a comprehensive investigation of the long-term projections (out to 2100) of conventional fossil fuel production drawn from the peer-reviewed scientific literature published since the year 2000 (i.e., after the original SRES scenarios were generated). In addition, for estimating the future production of the non-conventional fossil fuels, both the scientific literature and also reports from the mainstream energy institutes have been examined in order to account for the possible significant growth in the production of these non-conventional fossil fuels.

The production scenarios we present in this paper are based on investigation of the fossil fuel forecasts contained in the scientific literature and energy institute reports just mentioned. Then the emission factors for each type of fossil fuel are used to convert the fossil fuel production data we derive into carbon emissions. Then, in turn, these carbon emissions from fossil fuel production are combined with the assumed emissions from other sources to generate two supply-driven emission scenarios. Finally, a reduced-complexity and coupled carbon cycle and climate model, MAGICC 6.3, which has been calibrated to 19 CMIP3 AOGCM and $9 \mathrm{C}^{4}$ MIP carbon cycle models (Meinshausen et al., 2011a), is used to project the future climate change expected under the two different emission scenarios.

We use MAGICC as it has been a commonly used model in past IPCC assessments, and also as it provides sufficiently accurate global mean predictions of climate change under both SRES and RCP emission scenarios of the IPCC (Rogelj et al., 2012). Although the CMIP5 model has been more recently developed, and is used as the new model in the fifth IPCC assessment report (AR5), this progress in modeling, in terms of narrowing the uncertainties is limited and MAGICC can still provide largely consistent results with CMIP5 (Knutti and 
Sedlacek, 2013). Therefore we judge that, the conclusions of this paper, using MAGICC, would not change significantly if more recent models were used. Moreover, our results will be comparable with those from the mainstream institutes, such as the IPCC. A detailed description of MAGICC 6.3 can be found in Meinshausen et al. (2011a; 2011b).

\section{Supply-driven scenarios}

By reviewing the peer-reviewed literature published since the year 2000, we found and examined 36 long-term forecasts for the world's conventional oil production, 18 long-term forecasts for the world's conventional gas production, and 18 long-term forecasts for the world's coal production. These forecasts are shown in Appendix A.

Also, as mentioned previously, for forecasts of the global production of nonconventional hydrocarbon (i.e., oil and gas) resources, we investigated forecasts from both the peer-reviewed literature and from the mainstream energy institutes. By doing so, we found and examined 29 long-term production forecasts for non-conventional oil, and 15 longterm production forecasts for non-conventional gas. These forecasts are also shown in Appendix A.

By assuming that all these forecasts are equally likely, and by making a random assortment among these, we arrive at $11664(=36 \times 18 \times 18)$ and $435(=29 \times 15)$ different supply pathways for the global production of conventional and non-conventional fossil fuels, respectively. The mean values of these multiple pathways for the global production of conventional and non-conventional fossil fuel are shown in Figure 1.

The results of this analysis is that the mean forecast indicates that the global production of conventional fossil fuels will peak in 2028, at 11.42 Gtoe/yr, and also that the cumulative probability that this peak in the production of conventional fossil fuels will have occurred by 2050 is about $93.6 \%$. 
It is widely expected that the production of the non-conventional fossil fuels will see a rapid increase in future, and this is borne out by the forecasts by the mainstream institutes. For example, the US' EIA (2011) and the IEA (2012a) forecast that the production of the nonconventional fossil fuels will reach, respectively 1.75 Gtoe (Low and High cases: 1.63 - 2.05 Gtoe) by 2035, and 1.82 Gtoe (Low and High cases: 1.50 - 1.94 Gtoe). Based these forecasts and on other literature, our results suggest that the production of non-conventional fossil fuels will reach a mean forecast value of 1.82 Gtoe by 2035 , and with a $95 \%$ confidence interval of: 1.77-1.87 Gtoe, in keeping with the trends indicated by the mainstream institutes.

This rapid increase in the production of the non-conventional fossil fuels can indeed raise total global production of all fossil fuels, but we cannot expect this rise to continue for long, because of the approaching peak and subsequent decline in the production of the conventional fossil fuels. Based on the sources described above, we conclude that a very likely pathway for the total production of all fossil fuel resources in future is to keep increasing in next two decades to reach a maximum at $12.40 \mathrm{Gtoe} / \mathrm{yr}$, and then to decline. Therefore, the contribution of the non-conventional fossil fuels, though significant, is only to delay the appearance of the supply constraints of all fossil fuel resources, and to reduce the decline rate of total production after peak; but not to avoid such a peak completely (see Figure 1). The direct effect of this lack of increase in all fossil fuel supply is to limit the growth of annual $\mathrm{CO}_{2}$ emissions.

As mentioned previously, based on the analysis described above, we have generated two supply-driven carbon emission scenarios. The first is named the 'supply-driven peak conventional fossil fuels' scenario (labeled $S D-P C$ ). In this scenario, only $\mathrm{CO}_{2}$ emissions from conventional fossil fuels are considered. The second scenario is called the 'supplydriven peak conventional \& non-conventional fossil fuels' scenario $(S D-P C U)$. In this scenario the emissions from non-conventional fossil fuels are also included. There are two 
reasons for developing a $S D-P C$ scenario: one is to better compare our findings with literature, since most current literature only consider conventional fossil fuels; the other is to better understand the impacts of non-conventional fossil fuels on climate change, and where the $S D$ $P C$ scenario will be seen as a benchmark for comparison in this analysis. Total $\mathrm{CO}_{2}$ emissions from fossil fuels in our two SD scenarios are shown in Figure 2, and are compared to a number of SREC and RCP emissions pathways. It can be seen from this figure that the upper-bounds of the IPCC's 'demand-driven' SRES and RCP emission scenarios are significantly higher than the one presented in this paper.

Note that $\mathrm{CO}_{2}$ emissions from other (i.e., non fossil fuel) sources, and also other non$\mathrm{CO}_{2}$ emissions, are also included in these two SD scenarios. To be specific, $\mathrm{CO}_{2}$ emissions from cement production and gas flaring are assumed to keep changing with a constant proportion to the fossil $\mathrm{CO}_{2}$ emissions rate (Chiari and Zecca, 2011). $\mathrm{CO}_{2}$ emissions from land-use changes are expected to keep declining in future due to a slow-down in the deforestation rate and rising initiatives of reforestation (IPCC, 2007). Here, a 2.5\% annual decrease rate is applied to future $\mathrm{CO}_{2}$ emissions from land-use changes (Chiari and Zecca, 2011), where this ratio is also consistent with the latest observed data (Friedlingstein et al., 2010). For other non- $\mathrm{CO}_{2}$ GHG emissions, the median values of the RCPs are used (Meinshausen et al., 2011c).

\section{Results of climate projections}

\subsection{Simulation results}

We are now in a position to turn the above $\mathrm{CO}_{2}$ emissions levels into climate projections. Figure 3 shows the projected climate results obtained by using MAGICC 6.3. In the SD-PC scenario, and taking the median value, it can be seen that atmospheric $\mathrm{CO}_{2}$ concentration, and also the global-mean surface temperature, will keep increasing, and reach about $550 \mathrm{ppm}$ and 
$2.33{ }^{\circ} \mathrm{C}$, respectively, by 2100 . In the SD-PCU scenario, as would be expected both the atmosphere $\mathrm{CO}_{2}$ concentration and global-mean surface temperature are higher than for the SD-PC scenario, and reach median values of about $610 \mathrm{ppm}$ and $2.63{ }^{\circ} \mathrm{C}$, respectively, by 2100. Significantly, even in our low SD-PC scenario, the simulated results suggest that atmosphere $\mathrm{CO}_{2}$ concentration will be higher than $450 \mathrm{ppm}$, and the global-mean surface temperature increase higher than $2{ }^{\circ} \mathrm{C}$ this century. This result is in agreement with most climate studies, which indicate that the global climate system will exceed a dangerous level (taken as $450 \mathrm{ppm}$ and $2{ }^{\circ} \mathrm{C}$, respectively) this century even if only consuming current conventional fossil fuel resources (Meinshausen et al., 2009).

\subsection{Comparison with IPCC projections}

A comparison of climate projections under the SD scenarios generated in this paper and those under the IPCC SRES and RCPs scenarios is shown in Figure 4.

From this comparison, it is clear that climate results of IPCC scenarios, especially for their high-emission scenarios SRESA1FI and RCP8.5, appear extremely high. According to the IPCC scenarios, the median value of $\mathrm{CO}_{2}$ concentration and increase in global temperature can reach as high as about $1000 \mathrm{ppm}$ and about $4.8^{\circ} \mathrm{C}$ respectively by 2100 . However, our SD scenarios show that the likely upper-bound of median $\mathrm{CO}_{2}$ concentration and increase in global-mean surface temperature are only about $610 \mathrm{ppm}$ and $2.63{ }^{\circ} \mathrm{C}$ respectively by 2100 , even if considering rapid growth in the global production of the various non-conventional fossil fuels.

It is recognized that the actual likely climate changes may be larger than those indicated by the SD-PCU scenario because we assume, for simplification, that conventional and nonconventional fossil fuels have the same emission factors, while some of the literature indicates that the GHG footprint of the various non-conventional fossil fuel resources are 
higher than for the equivalent conventional resources (Howarth and Ingraffea, 2011; Weber and Clavin, 2012; Mckellar et al., 2009; Brandt and Farrell, 2007). For example, Howarth et al. (2011) claimed that life-cycle GHG emissions from shale gas are at least $30 \%$ more than those from conventional gas. However, this number is highly uncertain and could be only $3 \%$, according to Jiang et al. (2011). Due to this highly uncertainty and the same emission factors applied by mainstream institutes, this paper also uses the same emission factors for both conventional and non-conventional fossil fuels.

Thus overall, the results suggested by the SD-PCU scenario presented in this paper, and which is based on a wide range of 'supply-side' fossil fuel projections published since 2000, are in agreement with virtually all 'peak' studies, which concur that most climate projections made with current knowledge (i.e. given the range of similar climate models used within the mainstream institutes) overestimate future climate change due to making what appear to be unrealistic assumptions on the increase in usage of fossil fuels (Chiari and Zecca,2011).

Two reasons might be suggested to explain the IPCC's apparently extremely high projections. Firstly, that the global total resources of fossil fuels are treated as recoverable resources. As we mentioned in the Introduction, only the recoverable resources should be considered when forecasting crucial long-term production growth, and not the total resources. Rogner's reports (Rogner, 1997; Gregory and Rogner, 1998) are the main sources for the resource availability of fossil fuels used for generating the original IPCC's SRES. For deriving the RCPs, there was no analysis of fossil fuel resource availability. Therefore, the RCPs are probably implicitly assuming the same high resource availability as the SRES, or possibly even larger.

It should be noted that resource estimates in Rogner's reports are total resources because they include the resource category of 'additional occurrences'. For instance, gas hydrates are expected to provide energy supply assurance for the 21 st century due to large size of their 
resources (Majorowicz and Osadetz, 2001). However, 93.5\% of the total resources of gas hydrates are the additional occurrences (Rogner, 1997). Many analysts see the availability of such resources as being very unlikely, where the still-uncertain estimates of very large quantities of gas hydrates assumed worldwide have little to do with the likelihood that these hydrates will provide energy supply assurance for the future (Beauchamp,2004). Rogner himself agrees that these 'additional occurrences' should not be expected to be technically and economically recoverable before the end of this century (Rogner, 1997). For this reason, these 'additional occurrences' are excluded from the totals of potential energy supply assumed by many institutes.

A second reason why some of the IPCC SRES and RCPs look to be much on the high side is that it seems that generation of the original SRES may have treated resource exploitation as a stock problem instead of a flow problem. In the perspective of stock problem, future supply can essentially be determined by evaluating of the available stock (i.e. resource availability) in ground, and where fear of resource constraint to future supply can be dismissed if the stock of the fossil fuel is shown to be sufficiently large to meet assumed demand. For example, the IPCC (2000) conveys this notion by stating that "the sheer size of the fossil resource base makes fossil sources an energy supply option for many centuries to come." However, in the perspective of flow problem the stock in ground is of secondary importance, as it is flow rate of the resource that governs the supply to society. The clearest example of the difference in these two views is the many empirical studies that show that production flows of oil, gas and possibly of coal in most regions reach a peak when more than a half of recoverable resources still remain (Brandt, 2007). This lack of understanding of the phenomenon of 'mid-point' peak has bedeviled much of oil and gas forecasting to the present day.

\subsection{Comparison with current literature}


As mentioned previously, a number of studies in the literature have indeed paid attention to the potential impacts of supply-driven emissions scenarios on climate projections. Comparison of our projections made in this paper with those in the literature is shown in Figure 5. From this it can be seen that much of the rest of this 'supply-driven' literature suggests that future atmospheric $\mathrm{CO}_{2}$ concentration will likely peak in $21^{\text {st }}$ century. This contrasts with our results, which show no peak in $\mathrm{CO}_{2}$ concentration over this period. Indeed, as a result, some of the 'supply-driven analysis claims that dangerous climate change will be avoided (i.e. that atmospheric $\mathrm{CO}_{2}$ concentration will be lower than $450 \mathrm{ppm}$ over the entire $21^{\text {st }}$ century) due to the resource constraints on the production of fossil fuels (for example, Nel and Cooper, 2009). However, according to our projections, even in the SD-PC scenario, atmospheric $\mathrm{CO}_{2}$ concentration will exceed $450 \mathrm{ppm}$, and indeed reach about 550ppm by 2100. Furthermore, as Figure 5 shows, there are significant differences between the $\mathrm{CO}_{2}$ projections generated by this 'supply-driven' literature.

Two main reasons can be suggested to explain the differences in Figure 5. The first is that much of this class of literature does not give a comprehensive investigation of the future production of fossil fuels, especially of the non-conventional fossil fuels. For example, Nel and Cooper (2009) use Hubbert linearization (HL) to estimate the ultimate recoverable resources (URRs) of the various fossil fuels based on their historical production, and forecasts future production based on these URR values. However, a URR determined from historical data reflects largely only the production of conventional fossil fuels, since the production of non-conventional fossil fuels accounts for only a very small proportion to-date. This insufficient investigation of the future fossil fuels' production will result in different $\mathrm{CO}_{2}$ emission pathways, which are the basic input variables for climate models. Currently, although our study and most other literature show that the $\mathrm{CO}_{2}$ emissions from fossil fuels will peak in this century, the peak rate and peak date could differ significantly. 
The second reason for the different $\mathrm{CO}_{2}$ concentration projections shown in Figure 5 is the different nature of the climate models used. In broad terms, three types of climate models are used in current literature. These are: coupled carbon cycle and climate models (Brecha, 2008; Chiari and Zecca, 2011), the Bern carbon cycle models ('Bern CC') (Kharecha and Hansen, 2008), and empirical models (Nel and Cooper, 2009). For the first type of models, MAGICC 5.3 is the most widely used of these for current studies, although the version used in the literature quoted is not the latest. This type of model can generate not only the atmospheric $\mathrm{CO}_{2}$ concentration, but also the climate response, for example the changes in global-mean surface temperature. Bern CC models are simple carbon cycle models also widely used by mainstream institutes. However, this type of model is not coupled with climate change models, and therefore the ir results may not reflect the impacts of climate change on the global carbon cycle. There are also different versions of the Bern CC models, for example, the Bern CC model used by Kharecha and Hansen (2008) was originally built in 1996 (Joos et al, 1996), and where this model was also used in the second and third assessment reports of the IPCC. In IPCC's fourth assessment report (AR4), a new version of the Bern CC model is used (IPCC, 2007). Currently, the most recent version of the Bern CC model is that built by Joos et al. in 2012 (Joos et al., 2012). As opposed to the MAGICC model, the Bern $\mathrm{CC}$ models can only generate results in terms of atmospheric $\mathrm{CO}_{2}$ concentration, not the global-mean surface temperature also.

In addition to the above two types of models, some empirical models - built on actual data - have also been used in recent studies. For example, Nel and Cooper (2009) used three models in their paper, one of which is the Bern CC model which was also used for IPCC AR4, and the other two models were empirical models, namely $\mathrm{AH}(0.03)$ and $\operatorname{AL}(0.022)$. Tans (2009) also established an empirical model; however, his model structure is the same as the Bern CC model. 
To illustrate the impact of using these different models, in terms of their final results, we used these models to simulate the same emission scenarios; in this case the two SD emission scenarios developed in this paper. The results are shown in Figure 6. It can be seen from this figure that the impacts of the different models in terms of their forecast results are indeed significantly different. MAGICC 6.3 gives the highest simulation results. For example, the result under the SD-PC scenario shows atmospheric $\mathrm{CO}_{2}$ still rising by the end of the century, whereas for this same emission scenario the other models show either a move towards plateau, or else a clear peak in $\mathrm{CO}_{2}$ concentration around mid-century. The latest version of the Bern CC model (i.e., Joos et al., 2012-BernCC) gives simulation results close to those of MAGICC 6.3, but with a different growth pathway. The empirical models used by Nel and Cooper (2009) show the lowest results, and indeed are those that give a peak for atmosphere $\mathrm{CO}_{2}$ concentration in this century. Thus with the Nel+Cooper- $\mathrm{AH}(0.03)$ model the atmospheric $\mathrm{CO}_{2}$ concentration could be limited to under 450ppm, which is significantly lower than the results from the MAGICC 6.3 and those of the Bern CC models. The empirical model built by Tans (2009) shows similar results with the latest version of Bern CC model, the reason being, as mentioned, that the model structure is the same as the Bern CC model, although the parameters used are those estimated by the author. In addition, the models of Nel+Cooper are based on empirical analysis, and the results of the MAGICC 6.3 model are constrained by historical observed data, which is why both these types of model fit the historical data well.

The reason for this significant difference in the output of these current models, as indicated in Figure 6, can be explained by different assumptions on $\mathrm{CO}_{2}$ atmospheric lifetime, which is used to describe the remaining airborne fraction of emitted $\mathrm{CO}_{2}$ in the atmosphere after $\mathrm{t}$ years, because emitted $\mathrm{CO}_{2}$ will be partly absorbed gradually by a variety of natural sinks, such as terrestrial ecosystem uptake, or air-sea diffusion plus surface-deep ocean mixing (Zecca and Chiari, 2010). 
Generally, the remaining airborne fraction of emitted $\mathrm{CO}_{2}$ will decline rapidly in the first few years after the emission pulse, and then continue to decline but with a slower decline rate. Most models (see Figure 7) ind icate that about 37.2\% $\pm 3.9 \%$ of anthropogenic $\mathrm{CO}_{2}$ emissions remain in the atmosphere after 100 years and $21 \% \pm 2.3 \%$ after 1000 years. However, $\mathrm{Nel}+\mathrm{Cooper}-\mathrm{AH}(0.03)$ and $\mathrm{AL}(0.022)$ assume a very rapid uptake rate of emitted $\mathrm{CO}_{2}$, and that nearly all the emitted $\mathrm{CO}_{2}$ is absorbed after only 200 years (Figure 7).

Considering other scientific studies, it may be that Nel+Cooper- $\mathrm{AH}(0.03)$ and $\mathrm{AL}(0.022)$ models are overestimating the uptake capacity of natural sinks (Zecca and Chiari, 2010; Joos et al, 2012). Note however that the capacity of ocean uptake, the main natural sink, is decreasing because of the warming caused by increasing $\mathrm{CO}_{2}$ concentration in the atmosphere (Mckinley et al., 2011). It is for this reason that the IPCC is modifying its models, and increasing the remaining airborne fraction of emitted $\mathrm{CO}_{2}$ in the atmosphere (Joos et al., 2012). Except for the empirical models built by Nel and Cooper (2009), the lower uptake rate assumptions of the other models are consistent with current mainstream understanding of the carbon cycle as two-way transfers of carbon between different reservoirs and with different time scales (Joos et al.,2012). Most importantly, as mentioned, a relatively low uptake rate assumption is now being applied by IPCC. Therefore, to compare the projection results under SD scenarios with IPCC's results, and to know the impacts of fossil fuel supply constraints on climate change, it is suggested that models with the same assumptions in this area should be used to avoid the influence of different models assumptions on uptake on the projected results.

\section{Summary, Conclusions and Policy implications}

The following conclusions can be drawn: 
1) We assembled 116 long-term forecasts for the global production of fossil fuels (oil, gas or coal), using peer-reviewed literature published since 2000 , and recent reports from the mainstream energy forecasting agencies. These comprised 36 forecasts for conventional oil, 18 for conventional gas, 18 for coal, 29 for non-conventional oil and 15 for non-conventional gas. We assumed the forecasts to be equally likely, and statistically combined the range of possible combinations to yield median and probabilistic values for total global fossil fuel production. Two key forecasts were then generated: that for the global production of conventional fossil fuels (comprising conventional oil, conventional gas, and coal); and that for the global production of all fossil fuels (i.e., including also the production of nonconventional oil and gas).

According to these peer-reviewed literature, we find it is likely that the world production of conventional fossil fuels will reach a supply-limited maximum (i.e., 'peak') in this century. The production of non-conventional oil and gas is expected to increase rapidly in future, and hence increase the total fossil fuel production. However, the forecasts in the literature suggest that these contributions of non-conventional fossil fuels, though significant, will only delay the peak date of total fossil fuel production by some years. As a result, we conclude that supply constraints of fossil fuels supply are likely and should be considered in climate change projections.

2) We then calculate the $\mathrm{CO}_{2}$ emissions produced by these fuels. This is done by multiplying the global production of oil, gas and coal, respectively, by their $\mathrm{CO}_{2}$ emissions per quantity produced. This generates two fossil fuel supply-driven $\mathrm{CO}_{2}$ emission scenarios that are used in this paper: the 'SD-PC' scenario, which gives $\mathrm{CO}_{2}$ emissions from the global production of conventional fossil fuels; and the 'SD-PCU' scenario which gives $\mathrm{CO}_{2}$ emissions from the global production of all fossil fuels. We then input these $\mathrm{CO}_{2}$ emissions levels, plus allowance for non-fossil fuel GHG emissions, into the MAGICC 6.3 climate 
change model to calculate the expected resulting atmospheric $\mathrm{CO}_{2}$ concentration levels, and expected temperature changes above pre-industrial.

Based on this analysis, we find that supply constraints on total fossil fuels production are likely to provide an upper-bound to climate change over the time horizon considered in this paper (out to the end of 2100). Specifically, based on the SD-PCU emissions scenario, the median atmospheric $\mathrm{CO}_{2}$ concentration, and global-mean surface temperature increase, are likely to reach about $610 \mathrm{ppm}$ and $2.63{ }^{\circ} \mathrm{C}$ respectively by 2100 , even when the rapid growth in the production of the non-conventional fossil fuels (specifically, oil and gas) is considered. Note that these results are significantly lower than those projected by the IPCC under its earlier high-emission scenarios, such as SRESA1FI, or in its later high-concentration pathway of RCP8.5. Therefore, we conclude that the IPCC is likely to be overestimating the upper-bound of possible climate change over this time horizon; where this conclusion is supported by most of the 'peak fossil fuel production' studies published after the year 2000 that we examined.

3) If the contribution of the non-conventional fossil fuels is excluded, i.e. as in the SDPC scenario developed in this paper, we find that the median atmospheric $\mathrm{CO}_{2}$ concentration, and global-mean surface temperature increase, reach about $550 \mathrm{ppm}$ and $2.33{ }^{\circ} \mathrm{C}$ respectively by 2100 . Unfortunately, these results are significantly higher than the world's 'target' values of $450 \mathrm{ppm}$ and $2{ }^{\circ} \mathrm{C}$ increase that are the current goals of international effort. Therefore, we conclude that the supply constraints of fossil fuels production may be insufficient to solve the climate change problem. Overall, we conclude that future climate change may exceed currently proposed dangerous levels in this century even considering the production limits of the fossil fuel resources. This agrees with the conclusions reached by many other climate scientists. 
4) The differences within the current literature on expected climate change can be largely explained by the different assumptions made on the production growth of fossil fuels, and on different climate models then applied.

4.1) On the production growth of fossil fuels, some authors made their own forecasts, and used resource estimates based on limited sources of information. Furthermore, the fossil fuel production growth assumed in some of the literature appears to be only, or largely, that of the growth in conventional fossil fuels supply; and hence lacks proper consideration of the growth in the non-conventional fossil fuels. In order to present a more rigorous and complete supply-side analysis of the impact of fossil fuel use on climate change, we investigated the fossil fuel production growth forecasts for both conventional and non-conventional fossil fuels given in the scientific literature and in reports of mainstream energy institutes that have been published after 2000, that is after the date at which the original IPCC SRES scenarios were generated.

4.2) We then also examined aspects of the differences in the climate change models themselves. The differences in these models in terms of climate projections are significant, and should not be ignored. A significant part of the difference between some of the models we illustrated here lay in the $\mathrm{CO}_{2}$ residence times in the atmosphere assumed. To compare the impacts of the two fossil fuels supply-driven emissions projections generated within this paper (SD-PC and SD-PCU) with the IPCC's fossil fuels demand-driven projections (SRES and RCP), the latest version of MAGICC was used. Based on this, we expect that the conclusions in this paper are likely to be more robust than those in a number of other papers that have been published in the current literature.

5) We suggest that the robustness of findings presented here derives from the following: the wide range of post-2000 fossil fuel supply projections examined; the fact that we took account of both the growth in supply of the conventional as well as non-conventional fossil 
fuels; and the fact that we examined the outputs from a number of current recognized climate change models. But even so, of course uncertainties remain. Most of these apply to climate change modeling in general (such as economic assumptions; the correct handling of the complex feedbacks of the climate; $\mathrm{CO}_{2}$ residence time, and so on). But here we point out two uncertainties specific to this paper. These are:

5.1) That in the two emissions scenarios we use here we assume equal $\mathrm{CO}_{2}$ emissions from the conventional and non-conventional fossil fuels. We recognize that this is an oversimplification, though probably not large in terms of impact compared to some of the other uncertainties (as mentioned above) in this sort of climate change modeling.

5.2) That while the forecasts of supply of both conventional and non-conventional oil and gas as given in the literature may be thought of as being not too uncertain, the forecast for coal has to have an even greater degree of uncertainty attached. This is because various authors disagree significantly as to the extent that the known potentially very large resources of coal, especially that in thin or deep seams, and in non-bituminous coal, can be technically developed at any reasonable cost. Thus some forecasts see global coal supply as peaking (see Figure A3); while others see coal supply as being potentially very large if not constrained by measures to limit climate change.

Based on the above conclusions, here we summarize some policy implications that result, as follows:

1) Climate projections from a fossil fuels supply-side analysis should be considered into the international climate-change negotiations and in government decision making. Climate projections are the basis of international climate change negotiations. However, current 'mainstream' climate projections are still, we judge, based on a fossil fuels demand-side analysis. In this current mainstream analysis, the emission scenarios assumed cover a very 
wide range of future emissions, including those from extremely high fossil fuel usage, and where, importantly, these extremely high emission scenarios are seen as equally plausible as lower emission scenarios. This analysis thus has resulted in a large uncertainty range being attached to the final climate projections, which in turn implies a high risk, and cost, for decision-making. However, as we show in this paper, based on extensive literature published since 2000 on of the likely future constraints on global fossil fuels supply, the current extremely high fossil fuel usage scenarios should be excluded from consideration, or at least given a very low weighting.

2) Most people today see climate change and fossil fuel resource constraints as being two key challenges to be faced in the modern world (Friedrichs, 2011). A debate has taken place as to which is the more urgent, and hence should be given the greater attention. Based on the analysis in this paper, we find that climate change is the more urgent question. This is because even we ignore the likely contribution to fossil fuel supply of the non-conventional fossil fuels (in this case, of oil and gas), (i.e., in our SD-PC scenario), the exploitation of current conventional fossil fuels alone will be sufficient to make climate change exceed its currently-agreed dangerous level of $2{ }^{\circ} \mathrm{C}$ above pre-industrial level.

3) As a consequence, the world should be very cautious about the exploitation of the non-conventional fossil fuel resources. To deal with the resources shortage, many countries are trying to extract their own non-conventional fossil fuel resources, especially following the US shale oil and gas revolution. However, based on our analysis, extracting all of the current low-cost conventional fossil fuel resources alone will make climate change exceed the dangerous level, not to mention extracting the non-conventional fossil fuels. Therefore, if the world wants to control the climate change, extracting high-cost non-conventional fossil energy should be avoided. 
It should be noted that policy implications 2 and 3 proposed above are only based on this paper's projections, which are largely influenced by future fossil fuel usage and climate models. The most important contribution of this paper is to fully consider the future fossil fuel usage, and where the uncertainty of climate models is not considered in this study in any depth. Currently, there are still some studies claiming that climate models applied by mainstream institutes are incorrect and may overestimate climate change significantly (Hansen and Sato, 2004). Therefore, these policy implications do not necessarily reflect this uncertainty in climate models and should be treated with caution in practice. Improving the accuracy of climate models is still an important work in future climate studies.

\section{Acknowledgments}

This study has been supported by the Science Foundation of China University of Petroleum, Beijing (No.2462014YJRC024), National Natural Science Foundation of China (Grant No. 71503264; Grant No. 71373285; Grand No. 71303258), Humanities and Social Sciences Youth Foundation of the Ministry of Education of China (Grant No. 15YJC630121) and the Major Program of the National Social Science Found of China (Grant No. 13\&ZD159). The authors would like to thank Dr. Roger Bentley and Dr. Benjamin McLellan for modifying our paper and giving very helpful comments. We also received very helpful comments from the anonymous reviewers. 
Appendix A: Investigated long-term production trends for world fossil fuels

The published long-run forecast production trends for each type of fossil fuels that we have incorporated into this study are shown in Figures A1-A5. 


\section{References}

Alley, R.B., Marotzke, J., Nordhaus, W.D., Overpeck, J.T., \& Peteet, D.M., et al. (2003). Abrupt Climate Change. Science, 299, 2005-2010.

Arnell, N.W., Livermore, M.J.L., Kovats, S., Levy, P.E., \& Nicholls, R. et al. (2004). Climate and socio-economic scenarios for global-scale climate change impacts assessments: characterizing the SRES storylines. Global Environmental Change, 14, 3-20.

Arnell, N.W., Lowe, J. A., Brown, S., Gosling S. N., \& Gottschalk, P. et al. (2013). A global assessment of the effects of climate policy on the impacts of climate change. Nature Climate Change, 3(5):512-519.

Brecha, R.J. (2008). Emission scenarios in the face of fossil-fuel peaking. Energy Policy, 36, $3492-3504$.

Brecha, R.J. (2012). Logistic curves, extraction costs and effective peak oil. Energy Policy, 55, 586-597.

Brandt, A.R. (2007). Testing Hubbert. Energy Policy, 35, 3074-3088.

Brandt, A.R., \& Farrell, A.E. (2007). Scraping the bottom of the barrel: greenhouse gas emission consequences of a transition to low-quality and synthetic petroleum resources. Climatic Change, 84, 241-263.

Brandt, A.R., Plevin, R.J., \& Farrell, A.E. (2010). Dynamics of the oil transition: Modeling capacity, depletion, and emissions. Energy, 35, 2852-2860.

Beauchamp, B. (2004). Natural gas hydrates: myths, facts and issues. Comptes Rendus Geoscience, 336(9), 751-765.

Bentley, R.W., \& Bentley, Y. (2015). Explaining the Price of Oil 1971-2014 - The need to use reliable data on oil discovery and to account for 'mid-point' peak. Energy Policy, 86, 880-890.

BP (2013). BP Energy Outlook 2030. http://www.bp.com/en/global/corporate.html 
Bundesanstalt für Geowissenschaften und Rohstoffe(BGR) (2004). Reserves, Resources and $\begin{array}{llll}\text { Availability } & \text { of } & \text { Energy } & \text { Resources }\end{array}$ http://www.bgr.bund.de/EN/Home/homepage_node_en.html

Bundesanstalt für Geowissenschaften und Rohstoffe(BGR) (2011). Reserves, Resources and $\begin{array}{llll}\text { Availability } & \text { of } & \text { Energy } & \text { Resources }\end{array}$ http://www.bgr.bund.de/EN/Home/homepage_node_en.html

Campbell, C.J., \& Laherrere, H. (1998). The end of cheap oil. Scientific American, 278, 7883.

Chiari, L., \& Zecca, A. (2011). Constraints of fossil fuels depletion on global warming projections. Energy Policy, 39, 5026-5034.

de Almeida, P., \& Silva, P.D. (2011). Timing and future consequences of the peak of oil production. Futures, 43,1044-1055.

Doose, P. (2004). Projections of fossil fuel use and future atmospheric $\mathrm{CO}_{2}$ concentrations. The Geochemical Society Special Publications, 9, 187-195.

Dlugokencky, E., \& Tans, P. (2013). Globally averaged marine surface annual mean data. NOAA/ESRL. Available online at:〈ftp://ftp.cmdl.noaa.gov/ccg/co2/trends/co2_annmean_gl.txt $>$ (accessed 8 February 2013)

de Castro, C., Miguel, L.J., \& Mediavilla, M. (2009). The role of non-conventional oil in the attenuation of peak oil. Energy Policy, 37, 1825-1833.

Energy Information Administration of U.S. (EIA) (2011). International Energy Outlook 2011. September 19, 2011.

Etheridge, D.M., Steele, L.P., Langenfelds, R.L., Francey, R.J., \& Barnola, J-M. et al. (1996). Natural and anthropogenic changes in atmospheric $\mathrm{CO}_{2}$ over the last 1000 years from air in Antarctic ice and firn. Journal of Geophysical Research, 101, 4115-4128. 
ExxonMobil (2013). The outlook for energy: A view to 2040. Available at: http://corporate.exxonmobil.com/en/energy/energy-outlook

Friedrichs J. (2011). Peak energy and climate change: The double bind of post-normal science. Futures, 43, 469-477.

Friedlingstein, P., Houghton, R.A., Marland, G., Hackler, J., \& Boden, T.A. et al. (2010). Update on $\mathrm{CO}_{2}$ emissions. Nature Geosciences, 3, 811-812.

Garrett, T.J. (2011). Are there basic physical constraints on future anthropogenic emissions of carbon dioxide? Climatic Change, 104, 437-455.

Grubb, M. (2001). Who's afraid of atmospheric stabilization? Making the link between energy resources and climate change. Energy Policy, 29, 837-845.

Gregory, K., \& Rogner, H.H. (1998). Energy resources and conversion technologies for the 21st century. Mitigation and Adaptation Strategies for Global Change, 3(2-4), 171-230.

Gallagher, B. (2011). Peak oil analyzed with a logistic function and idealized Hubbert curve. Energy Policy, 34, 790-802.

Greene, D.L., Hopson, J.L., \& Li, J. (2006). Have we run out of oil yet? Oil peaking analysis from an optimist's perspective. Energy Policy, 34, 515-531.

Hansen, J., \& Sato, M. (2004). Greenhouse gas growth rates. Proceedings of the National Academy of Sciences of the United States of America, 101(46), 16109-16114.

Höök, M., \& Tang, X. (2013). Depletion of fossil fuels and anthropogenic climate changeA review. Energy Policy, 52, 797-809.

Hubbert, M.K. (1949). Energy from Fossil Fuels. Science, 109, 103-109.

Heinberg, R., \& Fridley, D. (2010). The end of cheap coal. Nature, 468, 367-369.

Howarth, R.W., \& Ingraffea A. (2011). Natural gas: Should fracking stop? Nature, 477, 271275. 
Howarth, R.W., Santoro, R., \& Ingraffea, A. (2011). Methane and the greenhouse-gas footprint of natural gas from shale formations. Climatic Change, 106(4), 679-690.

Höök, M., Zittel, W., Schindler, J., \& Aleklett, K. (2010). Global coal production outlooks based on a logistic model. Fuel, 89, 3546-3558.

Intergovernmental Panel on Climate Change(IPCC) (2000). Special report on emissions scenarios, Nakicenovic, N and Swart, R. (eds.). Cambrid ge University Press, Cambridge, UK.

Intergovernmental Panel on Climate Change(IPCC) (2001). Third Assessment Report: Climate Change 2001-synthesis report, Watson, R.T., Albritton, D.L., Barker, T., Bashmakov, I.A., Canziani, O., Christ, R., Cubasch, U., Davidson, O., Gitay, H., Griggs, D., Halsnaes, K. and Houghton, J. (eds.). Cambridge University Press, Cambridge, UK. Intergovernmental Panel on Climate Change(IPCC) (2007). Climate Change 2007: the physical science basis. In S. Solomon, D. Qin, M. Manning, Z. Chen, M. Marquis, K.B. Averyt, M. Tignor and H.L. Miller. (eds.). Cambridge University Press, Cambridge, UK. Intergovernmental Panel on Climate Change(IPCC) (2013). Climate Change 2013: the physical science basis. In Stocker, T.F., D. Qin, G.-K. Plattner, M. Tignor, S.K. Allen, J. Boschung, A. Nauels, Y. Xia, V. Bex and P.M. Midgley, (eds.). Cambridge University Press, Cambridge, UK.

International Energy Agency(IEA) (2008). Word Energy Outlook 2008. Available at: http://www.worldenergyoutlook.org.

International Energy Agency(IEA) (2012a). World Energy Outlook 2012. Available at: http://www.worldenergyoutlook.org.

International Energy Agency(IEA) (2012b). Golden Rules for a Golden Age of Gas: World Energy Outlook- Special Report on Unconventional Gas (2012b). Available at: http://www.iea.org/publications/freepublications/. 
Joos, F., Bruno, M., Fink, R., Stocker, T. F., \& Siegenthaler, U. et al. (1996). An efficient and accurate representation of complex oceanic and biospheric models of anthropogenic carbon uptake. Tellus, Ser. A and Ser. B, 48B, 397-417.

Joos, F., Roth, R., Fuglestvedt, J.S., Peters, G.P., \& Enting, I.G. et al. (2012). Carbon dioxide and climate impulse response functions for the compuation of greenhouse gas metric: a multi-model analysis. Atmos. Chem. Phys. Discuss., 12, 19799-19869.

Jackson, P.M. (2006). Why the "Peak Oil" theory falls down: Myths, legends, and the future of oil resources. Cambridge Energy Research Associates(CERA), 2006.

Jiang, M., Griffin, W.M., Hendrickson, C., Jaramillo, P., VanBriesen, J., \& Venkatesh, A. (2011). Life cycle greenhouse gas emissions of Marcellus shale gas. Environmental Research Letters, 6(3), 034014.

Kerr, R.A. (2011). Peak oil production may already be here. Science, 331 (6024), 1510-1511.

Krumdieck, S., Page, S., \& Dantas, A. (2010). Urban form and long-term fuel supply decline: A method to investigate the peak oil risks to essential activities. Transportation Research Part A: Policy and Practice, 44, 306-322.

Kharecha, P.A., \& Hansen, J.E. (2008). Implications of "peak oil" for atmospheric CO2 and climate. Global Biogeochemical Cycles, 22, 1-10.

Knutti, R., \& Sedlacek, J. (2013). Robustness and uncertainties in the new CMIP5 climate model projections. Nature Climate Change, 3, 369-373.

Kontorovich, A.E. (2009). Estimate of global oil resource and the forecast for global oil production in the 21st century. Russ. Geol. Geophys., 50, 237-242 (2009).

Laherrere, J.H. (2002a). Modelling future liquids production from extrapolation of the past and from ultimates. Energy Exploration and Exploit., 20, 457-479.

Laherrere, J.H. (2002b). Forecasting future production from past discovery. Int. J. Global Energy Issues, 18, 218-238. 
Moss, R.H., Edmonds, J.A., Hibbard, K.A., Manning, M.R., \& Rose, S.K., et al. (2010). The next generation of scenarios for climate change research and assessment. Nature, 463, 747-756.

Murray, J., \& King, D. (2012). Climate Policy: Oil's tipping point has passed. Nature, 481, 433-435.

Miller, R.G. (2011). Future oil supply: The changing stance of the International Energy Agency. Energy Policy, 39, 1569-1574.

Meadows, D.H., Randers, J., \& Meadows, D.L. (2004). Limits to Growth: The 30-Year Update. Chelsea Green Publishing Co., White River Junction, Vermont, 2004.

Meinshausen, M., Meinshausen, N., \& Hare, W., et al. (2009). Greenhouse-gas emission targets for limiting global warming to $2^{\circ} \mathrm{C}$. Nature, 458(7242),1158-1162.

Meinshausen, M., Raper, S., \& Wigley, T. (2011a). Emulating coupled atmosphere-ocean and carbon cycle models with a simpler model, MAGICC6-Part 1: Model description and calibration. Atmos. Chem. Phys., 11, 1417-1456.

Meinshausen, M., Wigley, T., \& Raper, S. (2011b). Emulating atmosphere-ocean and carbon cycle models with a simpler model, MAGICC6-Part 2: Applications. Atmos. Chem. Phys., $11,1457-1471$

Meinshausen, M., Smith, S. J., Calvin, K., Daniel, J.S., \& Kainuma, M.L.T., et al. (2011c). The RCP Greenhouse Gas Concentrations and their Extension from 1765 to 2300. Climatic Change, 109, 213-241.

McKellar, J., Charpentier, A.D., Bergerson, J.A., \& MacLean, H.L. (2009). A life cycle greenhouse gas emissions perspective on liquid fuels from unconventional Canadian and US fossil sources. Int. J. Global Warm., 1, 160-178.

Majorowicz, J.A., \& Osadetz, K.G. (2001). Gas hydrate distribution and volume in Canada. Amer. Assoc. Petrol. Geol. Bull., 85, 1211-1230. 
Mckinley, G.A., Fay, A.R., Takahashi, T., \& Metzl, N. (2011). Convergence of atmospheric and North Atlantic carbon dioxide trends on multidecadal timescales. Natural Geoscience, 4, 606-610.

Maggio, G., \& Cacciola, G. (2009). A variant of the Hubbert curve for world oil production forecasts. Energy Policy, 37, 4761-4770.

Maggio, G., \& Cacciola, G. (2012). When will oil, natural gas, and coal peak? Fuel, 98, 111123.

Mohr, S.H., \& Evans, G.M. (2007a). Mathematical model forecasts year conventional oil will peak. Oil Gas J., 105, 45-46.

Mohr, S.H., \& Evans, G.M. (2007b). Model proposed for world conventional, unconventional gas. Oil Gas J., 105, 46-51.

Mohr, S.H., \& Evans, G.M. (2008). Peak oil: Testing Hubbert's curve via theoretical modeling. Nat. Resour. Res., 17, 1-11.

Mohr, S.H., \& Evans, G.M. (2009). Forecasting coal production until 2100. Fuel, 88, 20592067.

Mohr, S.H., \& Evans, G.M. (2010a). Combined Generalized Hubbert-Bass Model Approach to Include Disruptions When Predicting Future Oil Production. Natural Resources, 1, 2833.

Mohr, S.H., \& Evans, G.M. (2010b). Long term prediction of unconventional oil production. Energy Pol., 38, 265-276.

Mohr, S.H., \& Evans, G.M. (2011). Long term forecasting of natural gas production. Energy Policy, 39, 5550-5560.

Nel, W.P., \& Cooper, C.J. (2009). Implications of fossil fuel constraints on economic growth and global warming. Energy Policy, 37 (1), 166-180. 
Nel, W.P., \& van Zyl, G. (2010). Defining limits: energy constrained economic growth. Applied Energy, 87 (1), 168-177.

Newbery D. (2011). Oil shortages, climate change and collective action. Phil. Trans. R. Soc. A., 369, 1748-1761.

Nashawi, I.S., Malallah, A., \& Al-Bisharah, M. (2010). Forecasting world crude oil production using multicyclic Hubbert model. Energy Fuels, 24, 1788-1800.

Organization of the Petroleum Exporting Countries(OPEC) (2012). World Oil Outlook 2012. http://www.opec.org/opec_web/en/publications/340.htm

Patzek, T., \& Croft, G. (2010). A global coal production forecast with multi-Hubbert cycle analysis. Energy, 35, 3109-3122.

Rogner, H.H. (1997). An assessment of world hydrocarbon resources. Annual review of energy and the environment, 22(1), 217-262.

Rogelj, J., Meinshausen, M., \& Knutti, R. (2012). Global warming under old and new scenarios using IPCC climate sensitivity range estimates. Nature Climate Change, 2, 248-253.

Rehrl, T., \& Friedrich, R. (2006). Modelling long-term oil price and extraction with a Hubbert approach: The LOPEX model. Energy Policy, 34, 2413-2428.

Rutledge, D. (2011). Estimating long-term world coal production with logit and probit transforms. Int. J. Coal Geology, 85, 23-33.

Stott, P.A., \& Kettleborough, J.A. (2002). Origins and estimates of uncertainty in predictions of twenty-first century temperature rise. Nature, 416, 723-726.

Sweetnam, G. (2008). Long-term Global Oil Scenarios: Looking Beyond 2030. EIA 2008 Energy Conference, Washington, DC. April 7, 2008.

Tans, P. (2009). An accounting of the observed increase in Oceanic and Atmospheric CO2 and an outlook for the future. Oceanoraphy, 22 (4), 26-35. 
Tans, P. (2013). Mauna Loa $\mathrm{CO}_{2}$ annual mean data, NOAA/ESRL. Available online at:<ftp://ftp.cmdl.noaa.gov/ccg/co2/trends/co2_annmean_mlo.txt $>$ (accessed 8 February 2013)

Tsoskounogloua, M., Ayeridesb, G., \& Tritopouloub, E. (2008). The end of cheap oil: Current status and prospects. Energy Policy, 36, 3797-3806.

Vernon, C., Thompson, E., \& Cornell, S. (2011). Carbon dioxide emission scenarios: limitations of fossil fuels resource. Procedia Environmental Sciences, 6, 206-215.

Valero, A., \& Valero, A. (2010). Physical geonomics: Combining the exergy and Hubbert peak analysis for predicting mineral resources depletion. Resources, Conservation and Re., 54, 1074-1083.

Valero, Al., \& Valero, A. (2011). A prediction of the exergy loss of the world's mineral reserves in the 21st century. Energy, 36, 1848-1854.

Webster, M.D., Babiker, M., Mayer, M., Reilly, J.M., \& Hamisch, J. et al. (2002). Uncertainty in emission projections for climate models. Atmospheric Environment, 36(22), 3659-3670.

Ward, J.D., Mohr, S.H., Myers, B.R., \& Nel, W.P. (2012). High estimates of supply constrained emissions scenarios for long-term climate risk assessment. Energy Policy, 51, 598-604.

Ward, J.D., Werner, A.D., Nel, W.P., \& Beecham, S. (2011). The influence of constrained fossil fuels emissions scenarios on climate and water resources projections. Hydrol. Earth Syst. Sci., 15, 1879-1893.

Weber, C.L., \& Clavin, C. (2012). Life Cycle Carbon Footprint of Shale Gas: Review of Evidence and Implications. Environ. Sci. Technol., 46, 5688-6595. 
Wang, J.L., Feng, L.Y., Zhao, L., Snowden, S., \& Wang, X. (2011). A comparison of two typical multicyclic models used to forecast the world's conventional oil production. Energy Policy, 39, 7616-7621.

York, R. (2012). Asymmetric effects of economic growth and decline on $\mathrm{CO}_{2}$ emission. Nature Climate Change, 2, 762-764.

Zhao, L., Feng, L.Y., \& Hall, C.A.S. (2009). Is peakoillism coming? Energy Policy, 37 (6), 2136-2138.

Zecca, A., \& Chiari, L. (2010). Fos sil-fuels constraints on global warming. Energy Policy, 38, $1-3$.

Zerta, M., Schmidt, P.R., Stiller, C., \& Landinger, H. (2008). Alternative World Energy Outlook (AWEO) and the role of hydrogen in a changing energy landscape. Int. J. Hydrogen Energy, 33, 3021-3025. 


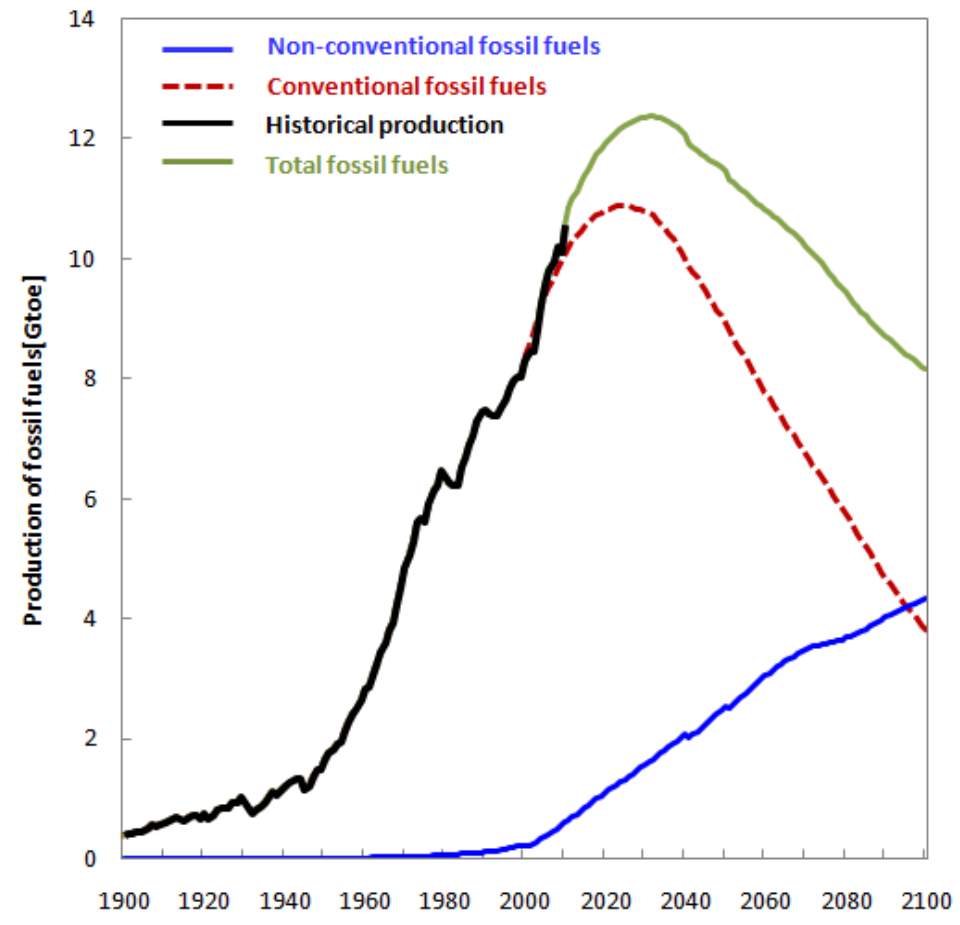

Figure 1. Mean value of expected future supply of global fossil fuel resources, based on peer-reviewed literature and on forecasts from the mainstream energy institutes. Note that the production of coal is treated as solely a conventional fossil fuel; while both oil and gas production have conventional and non-conventional components. 


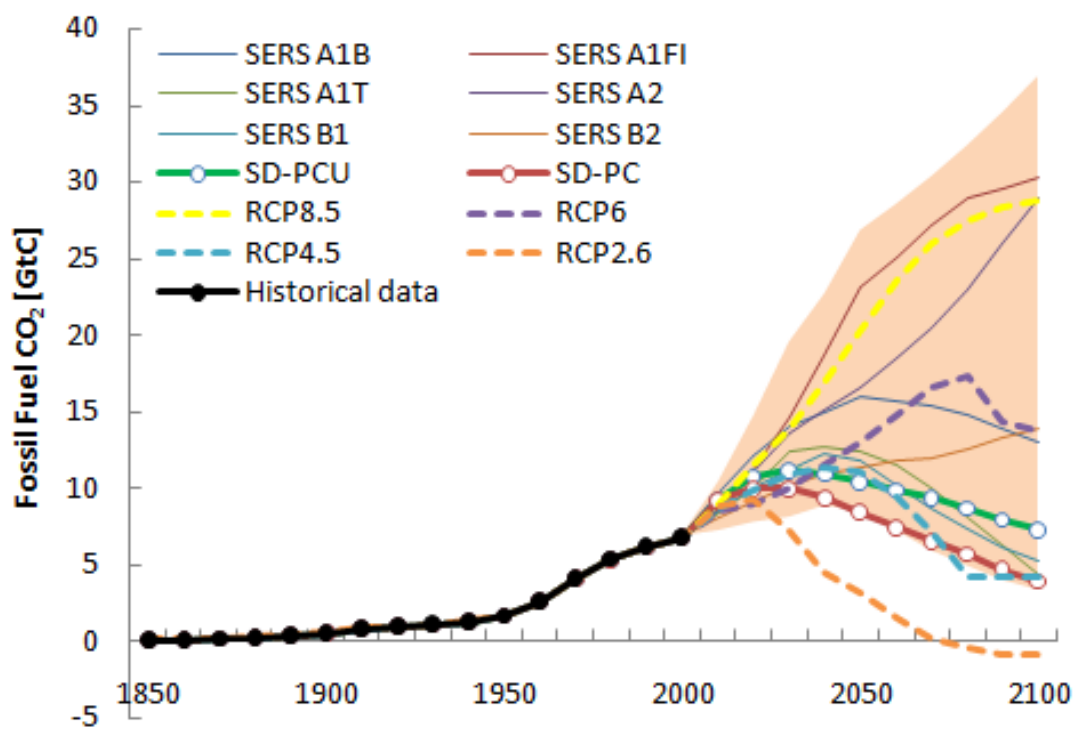

Figure 2. Comparison of total $\mathrm{CO}_{2}$ emissions from fossil fuels in the two SD scenarios generated in this paper and those in the IPCC SRES and RCP scenarios/pathways. Shadow area is the range of 40 SRES scenarios. $\mathrm{CO}_{2}$ emissions from fossil fuels are calculated by multiplying the production by an average emission factors (coal: $1.08 \mathrm{GtC} / \mathrm{Gtoe}$; gas: $0.6409 \mathrm{GtC} / \mathrm{Gtoe}$; oil: $0.8737 \mathrm{GtC} / \mathrm{Gtoe})$. Note that the SD scenarios presented here are based on fossil fuel forecasts published since 2000, i.e., after the date at which the SRES scenarios were generated. The RCPs were generated more recently, but largely reflect the assumptions used for the SRES scenarios. 

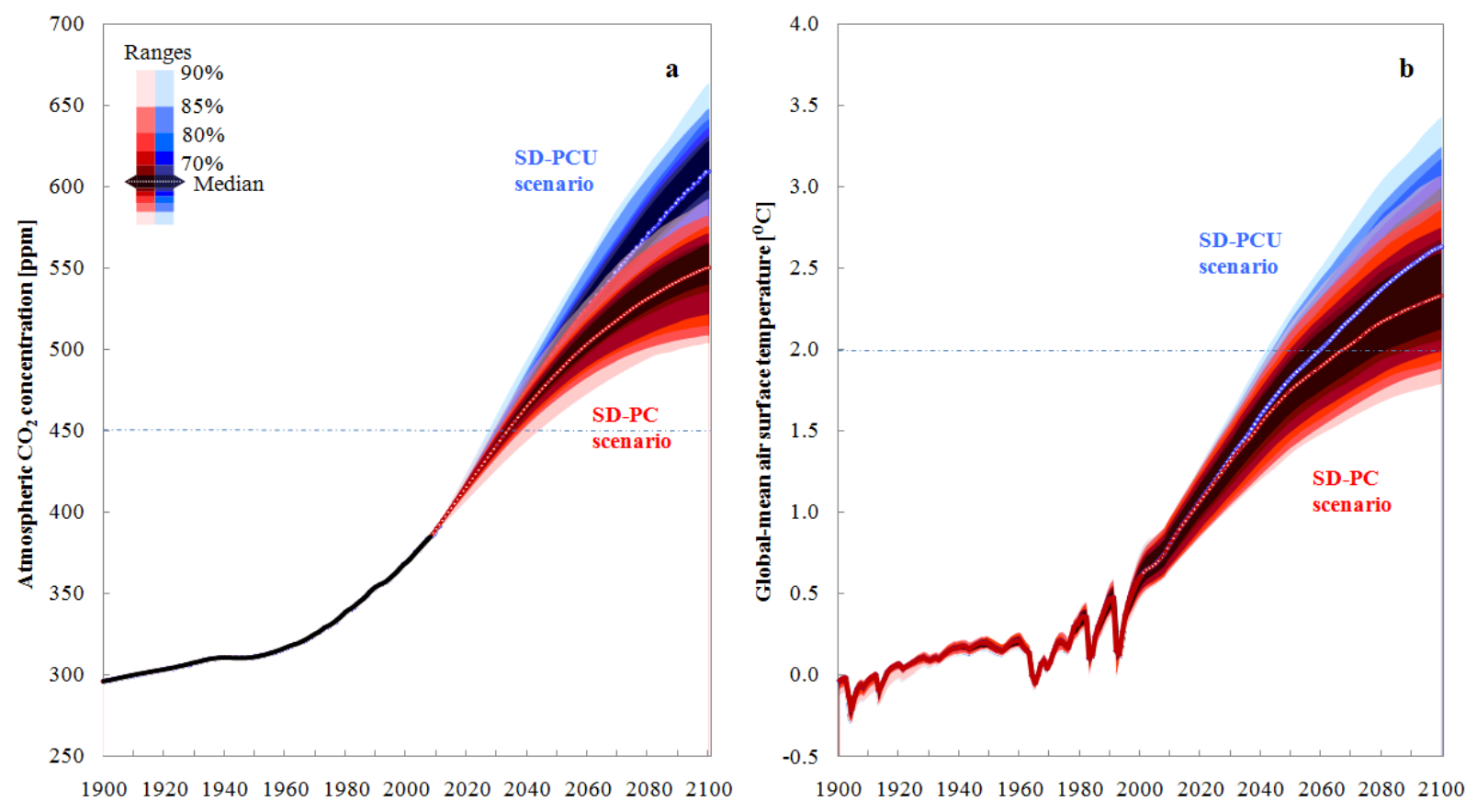

Figure 3. Probabilistic values for atmospheric $\mathrm{CO}_{2}$ concentration and twe nty-first century global-mean surface tempe rature under our two SD scenarios; (a), Atmospheric $\mathrm{CO}_{2}$ concentration based on the SD scenarios; (b), Corresponding global-mean surface temperature relative to pre-industrial level. (The color range shown in $\mathbf{a}$ also applies to $\mathbf{b}$; solid lines indicate the median values for each of the two scenarios) 

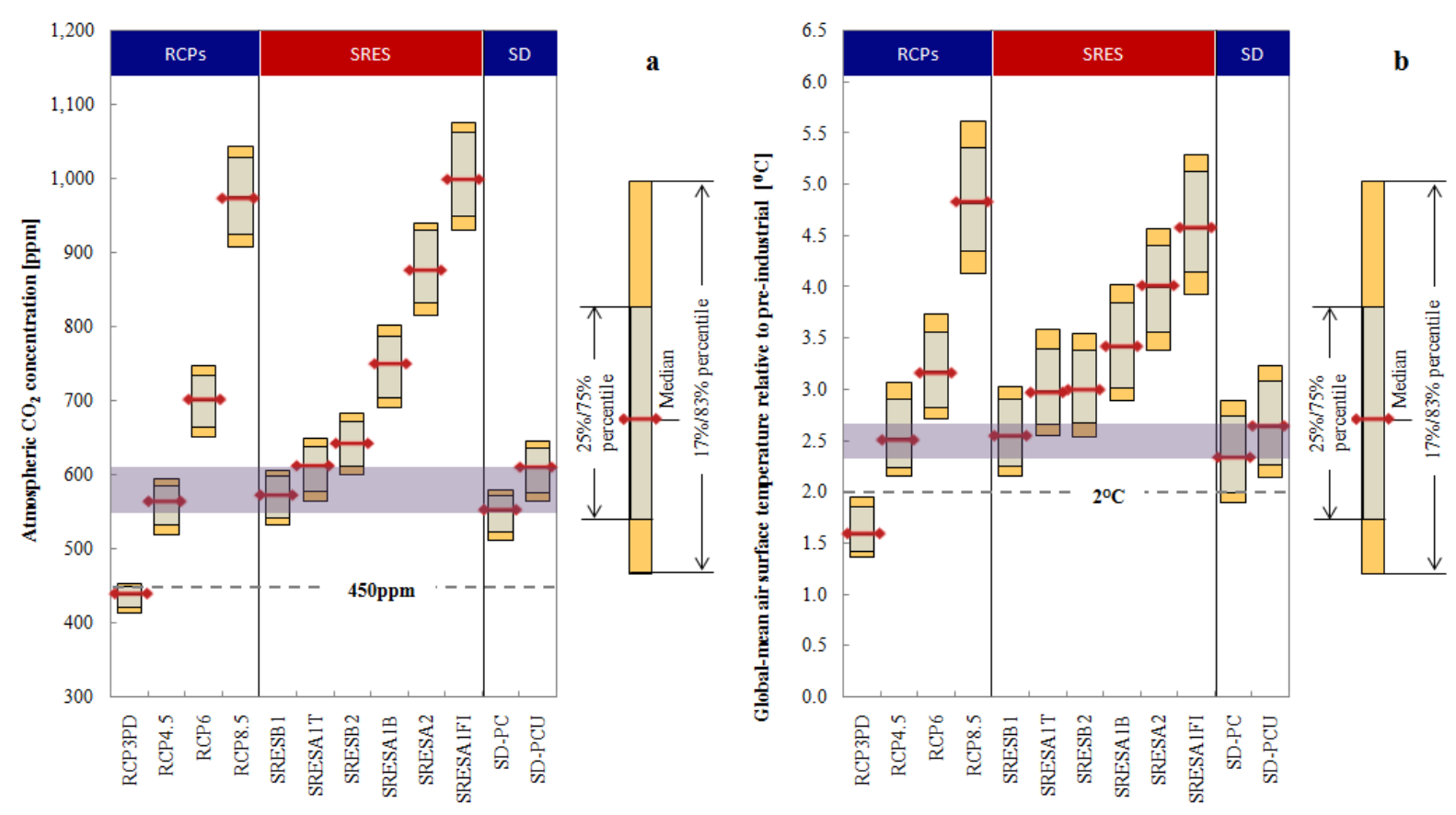

Figure 4. Comparison of atmospheric $\mathrm{CO}_{2}$ concentration and twenty-first century global-mean temperature resulting from the two SD scenarios generated in this paper, and with those of the IPCC SRES and RCP. (a), Atmospheric $\mathrm{CO}_{2}$ concentration; (b), Global-mean surface temperature increase. 


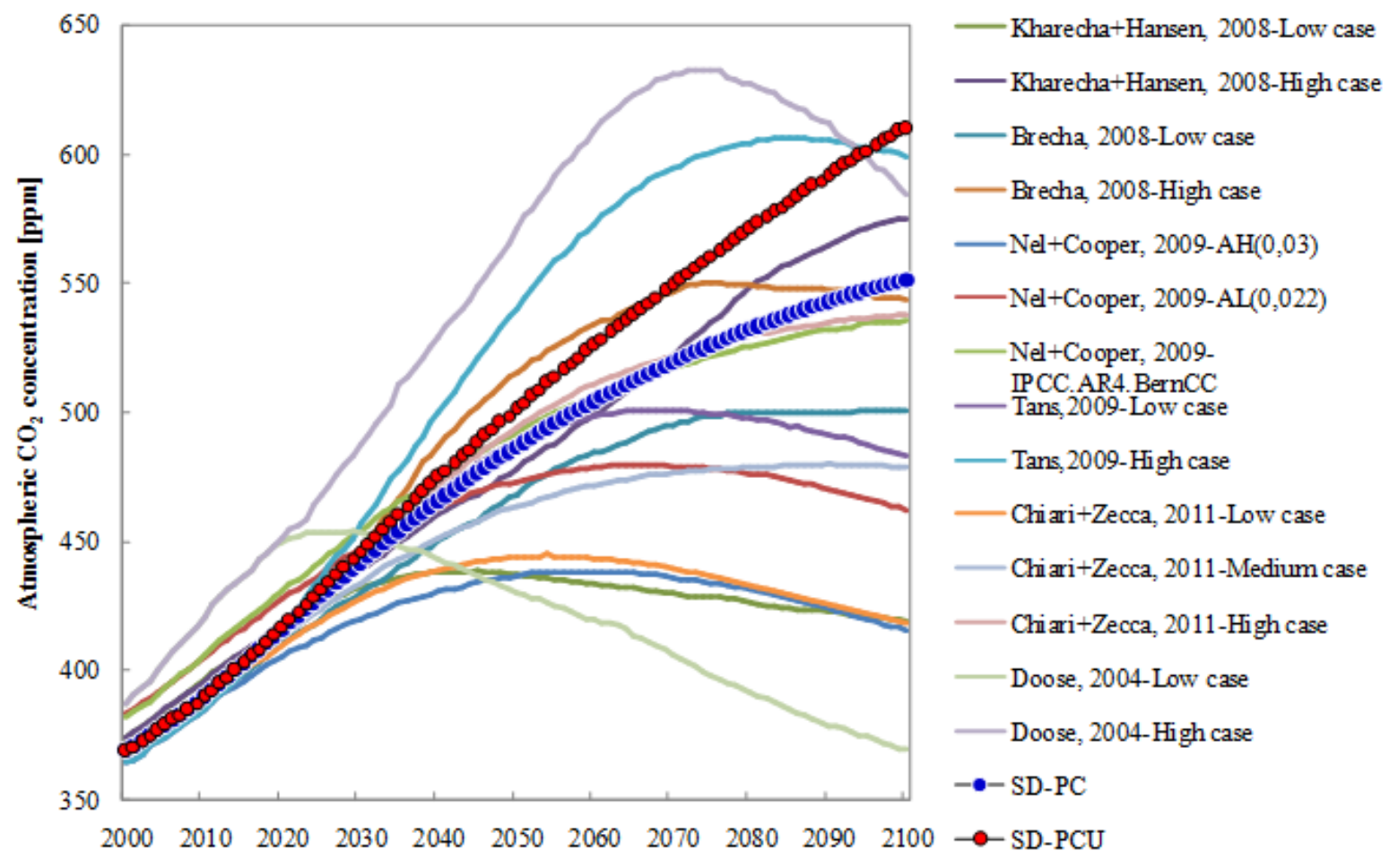

Figure 5. Comparison of atmos pheric $\mathrm{CO}_{2}$ concentration under SD scenarios with those from a range of current lite rature that examines 'supply-driven' fossil fuel emission scenarios. Data sources: Doose (2004), Brecha (2008), Kharecha and Hansen (2008), Nel and Cooper (2009), Tans (2009), Chiari and Zecca (2011). 

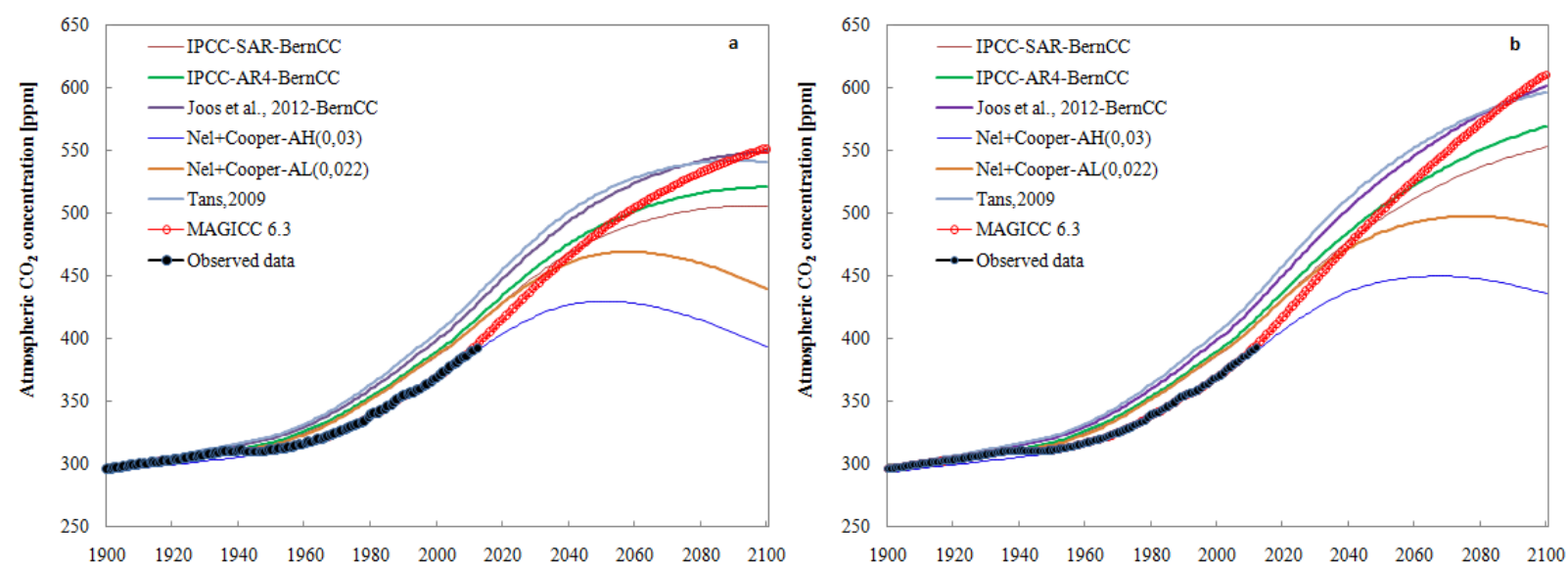

Figure 6. Comparison of atmospheric $\mathrm{CO}_{2}$ concentrations forecast based on the models used by recent related literature: (a), Atmospheric $\mathrm{CO}_{2}$ concentration under the SD-PC scenario; (b), Atmospheric $\mathrm{CO}_{2}$ concentration under the SD-PCU scenario. Observed data are based on Law Dome data, 1850-1958 (Etheridge et al., 1996), Maunna Loa data, 1959-1979 (Tans, 2013), and on global average data, 1980-2012 (Dlugokencky and Tans, 2013). The detailed equations of these models can be found in Kharecha and Hansen (2008), IPCC (2007), Joos et al. (2012), Nel and Cooper (2009) and Tans (2009). 


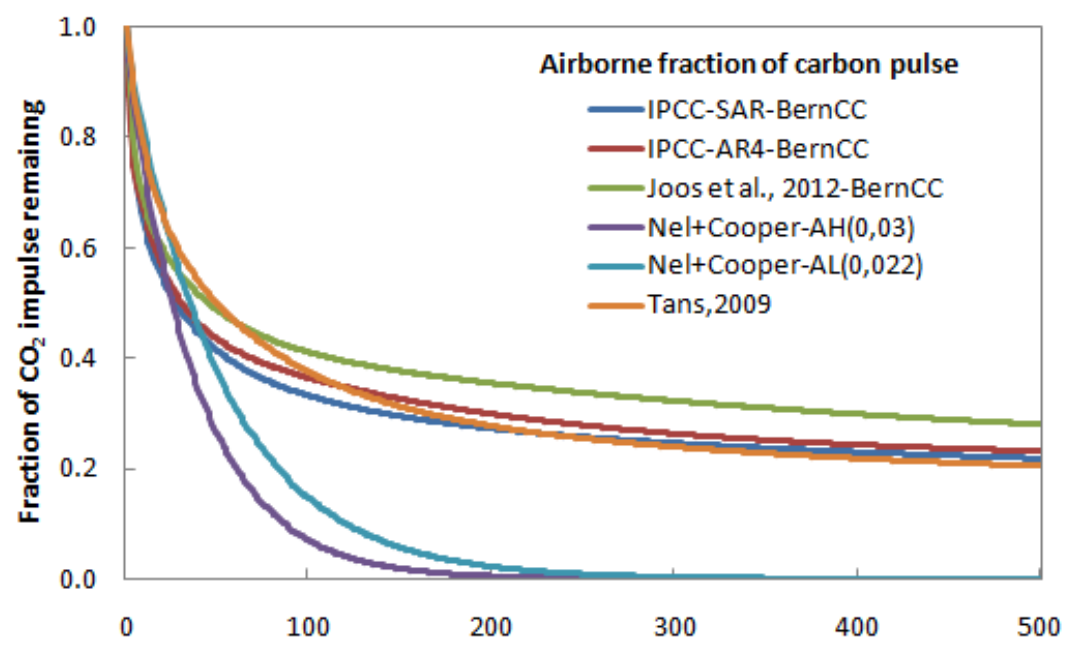

Figure 7. Comparison of the percentage of emitted $\mathrm{CO}_{2}$ remaining in the atmosphere after $t$ years, as assumed in the different models. 


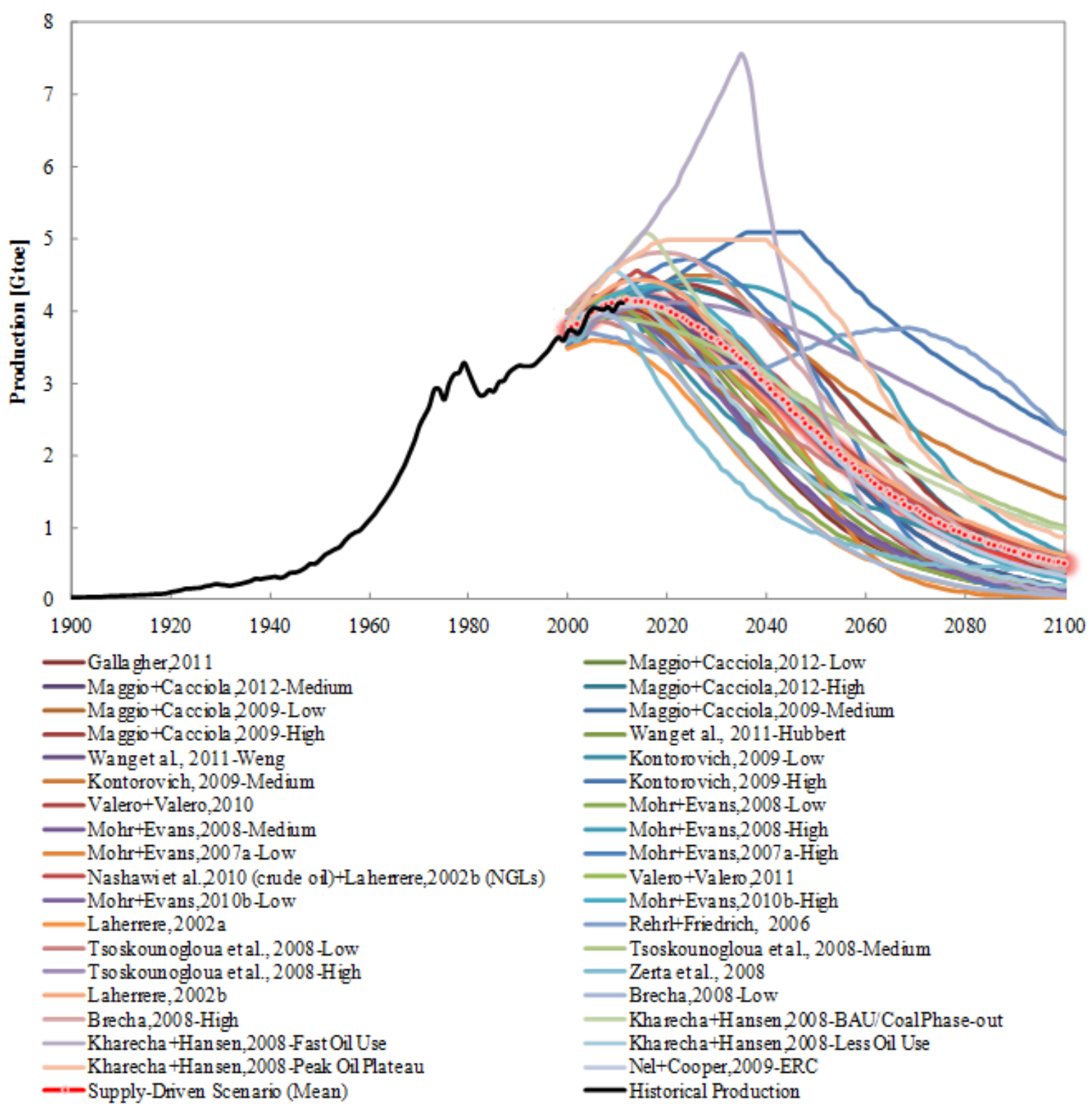

Figure A1. Thirty-six long-term production scenarios for the annual production of world conventional oil, drawn from peer-reviewed literature published since the year 2000. Data sources: Gallagher (2011), Maggio and Cacciola (2012, 2009), Wang et al. (2011), Kontorovich (2009), Valero and Valero (2010, 2011), Mohr and Evans (2008, 2007a,2010a), Nashawi and Malallah (2010), Laherrère (2002a,2002b), Rehrl and Friedrich (2006), Tsoskounogloua et al. (2008), Zerta et al. (2008), Brecha (2008), Kharecha and Hansen (2008), Nel and Cooper (2009). 


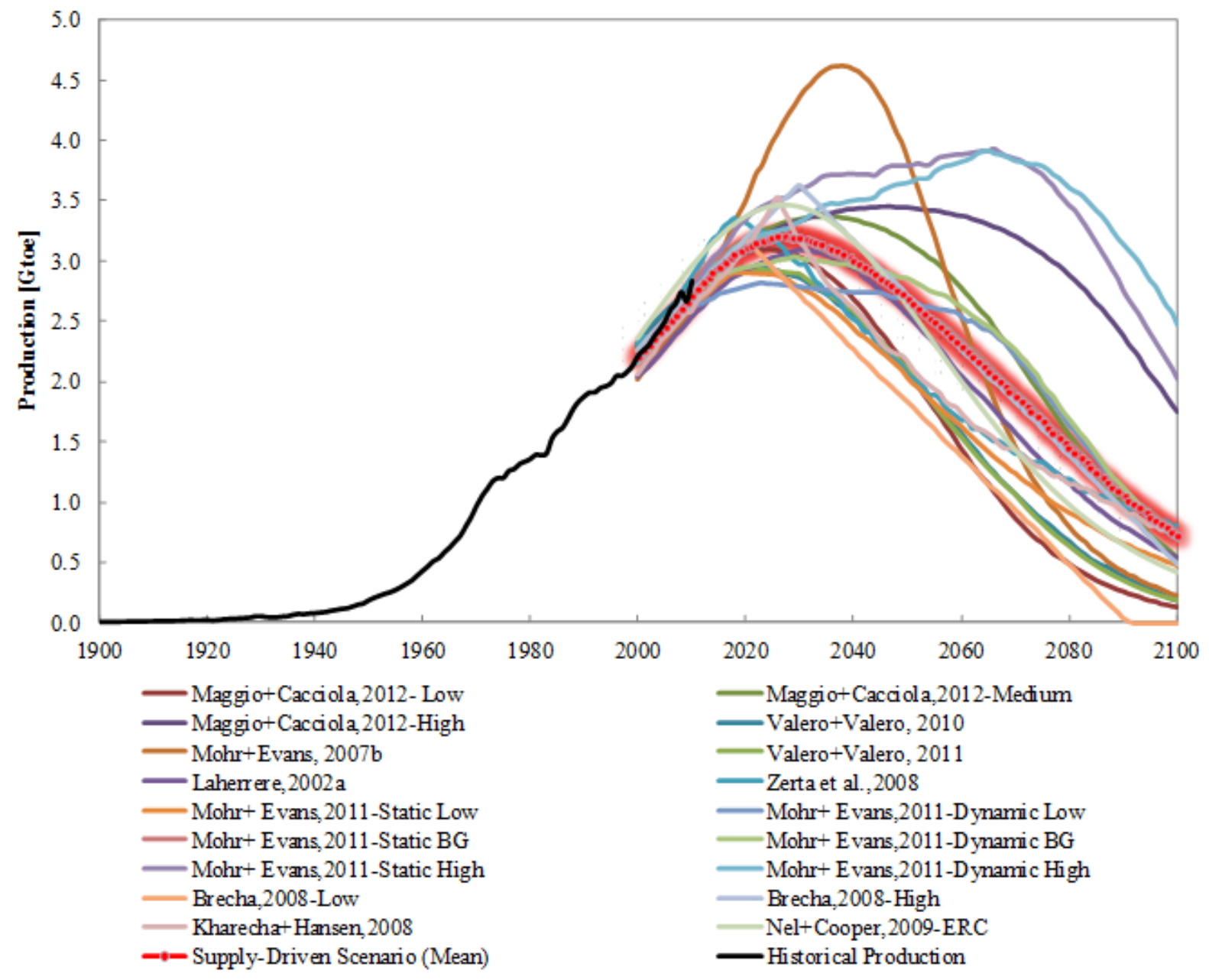

Figure A2. Eighteen long-term production scenarios for the annual production of world conventional gas, drawn from peer-reviewed literature published since the year 2000. Data sources: Maggio and Cacciola (2012), Valero and Valero (2010, 2011), Laherrere (2002b), Zerta et al. (2008), Brecha (2008), Kharecha and Hansen (2008), Nel and Cooper (2009), Mohr and Evans (2007b, 2011). 


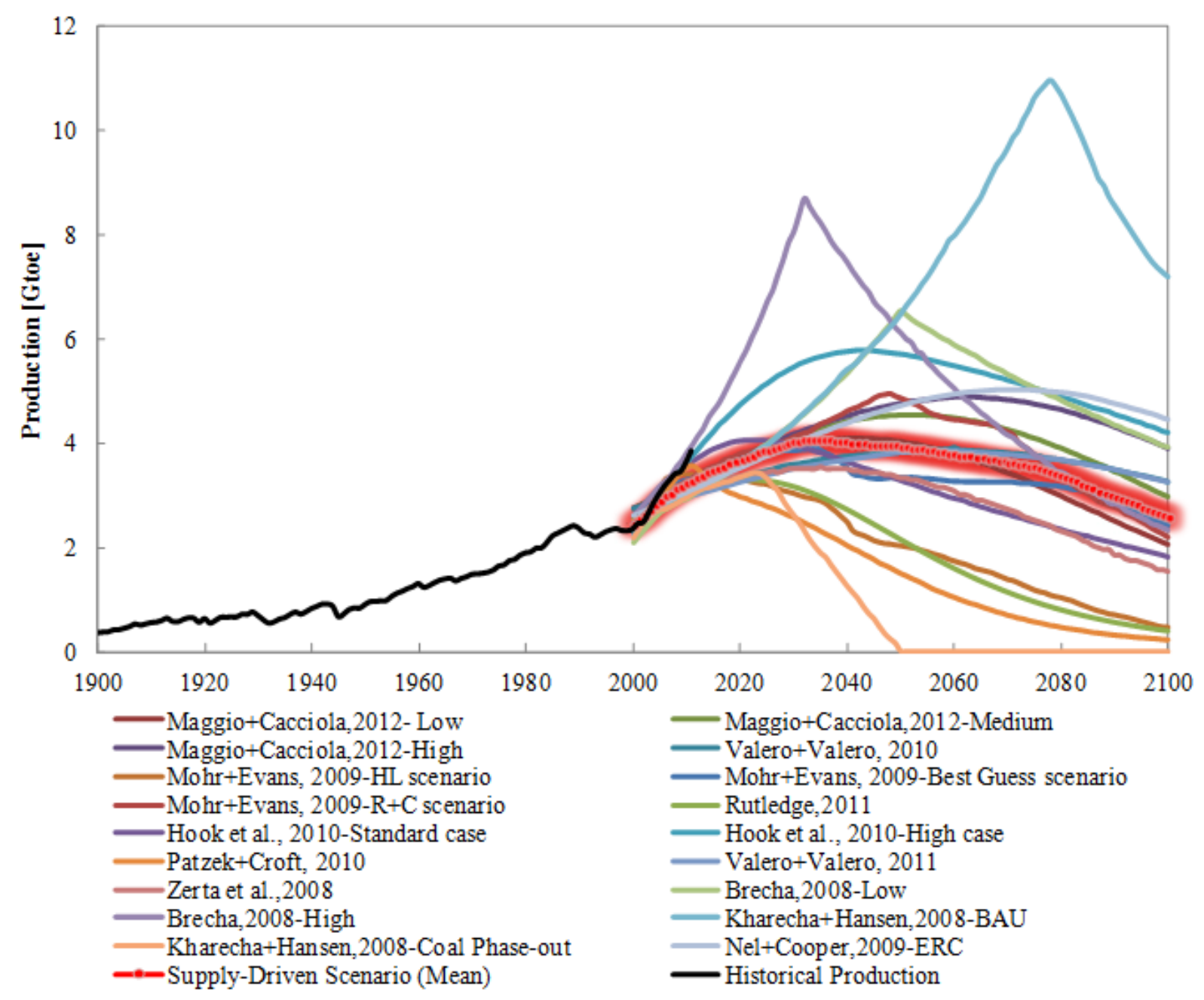

Figure A3. Eighteen long-term production scenarios for the annual production of world coal, drawn from peer-reviewed literature publis hed since the year 2000. Note: Forecasts for coal production are especially uncertain. While undoubtedly large volumes of coal exist as resources, particularly in thin and deep seams, and also as non-bituminous coal, it is not well established how much of these resources constitute recoverable resources under any realistic scenarios on the future price of coal, and on technology levels. It is recognized that increased automation, and use of in-situ recovery methods can - at least in principle - access large quantities of the coal currently considered uneconomic to extract. Data sources: Maggio and Cacciola (2012), Valero and Valero (2010, 2011), Brecha (2008), Kharecha and Hansen (2008), Nel and Cooper (2009), Mohr and Evans (2009), Rutledge (2011), Höök et al. (2010), Patzek and Croft (2010). 


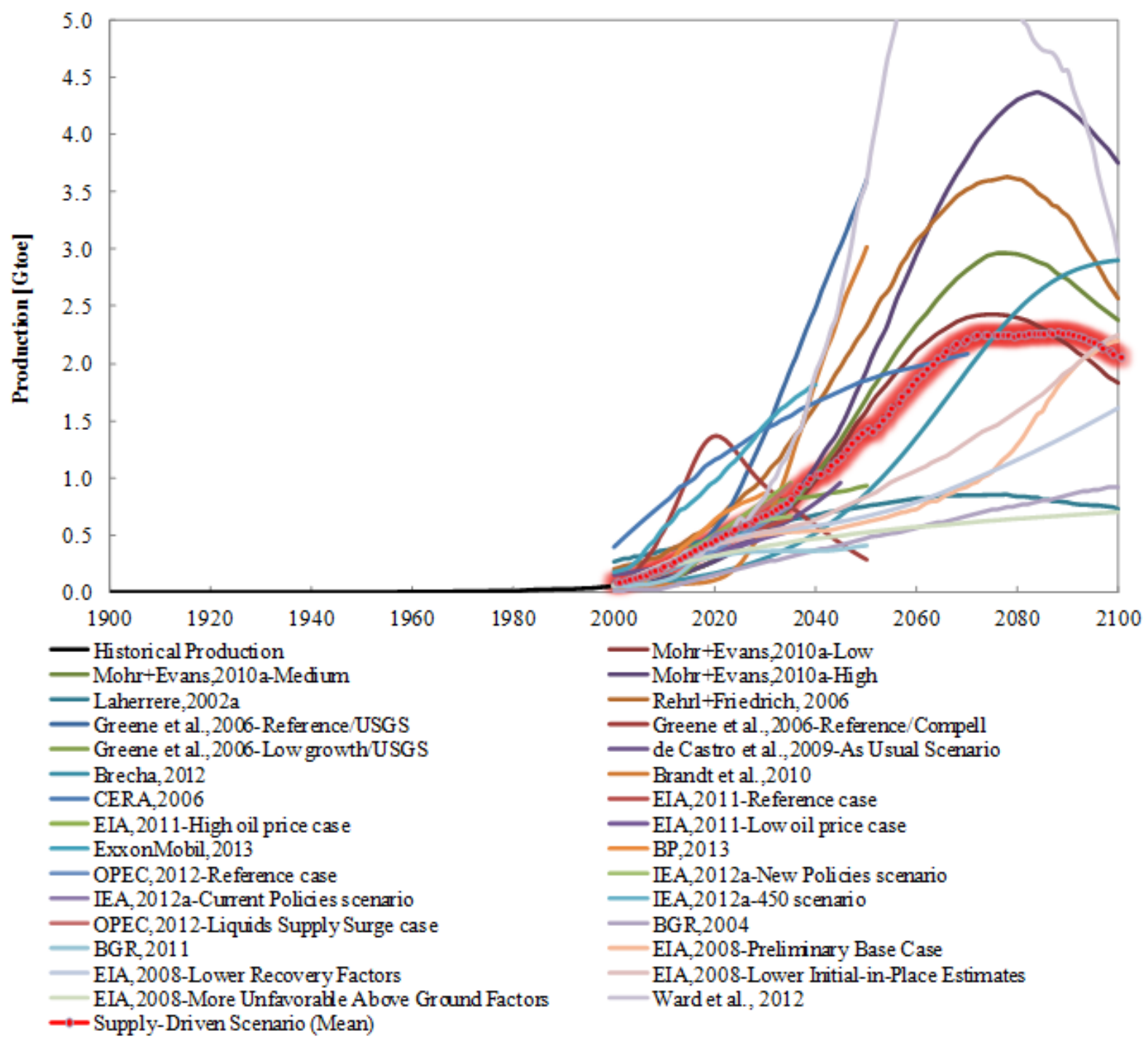

Figure A4. Twenty-nine long-term production scenarios for the annual production of world unconventional oil, drawn from peer-revie wed lite rature and mainstream energy institutes' reports published since the year 2000. Note: the very high curve shown in this figure is from Ward et al. (2012). The purpose of Ward et al. (2012) is to overestimate the potential supply of fossil fuels. To do so, they first consider all kinds of fossil fuel resources, such as gas hydrates, and then, they assume that the recoverable resources of these fossil fuels are extremely large and the growth rate for future production is very high (see detailed description in Ward et al. (2012)). Data sources: Laherrere (2002b), Rehrl and Friedrich (2006), Mohr and Evans (2010b), Greene et al. (2006), de Castro et al. (2009), Brecha (2012), Brandt et al. (2010), Jackson (2006), EIA (2011), ExxonMobil (2013), BP (2013), OPEC (2012), IEA (2012a), BGR (2004,2011), Sweetnam (2008), Ward et al. (2012). 


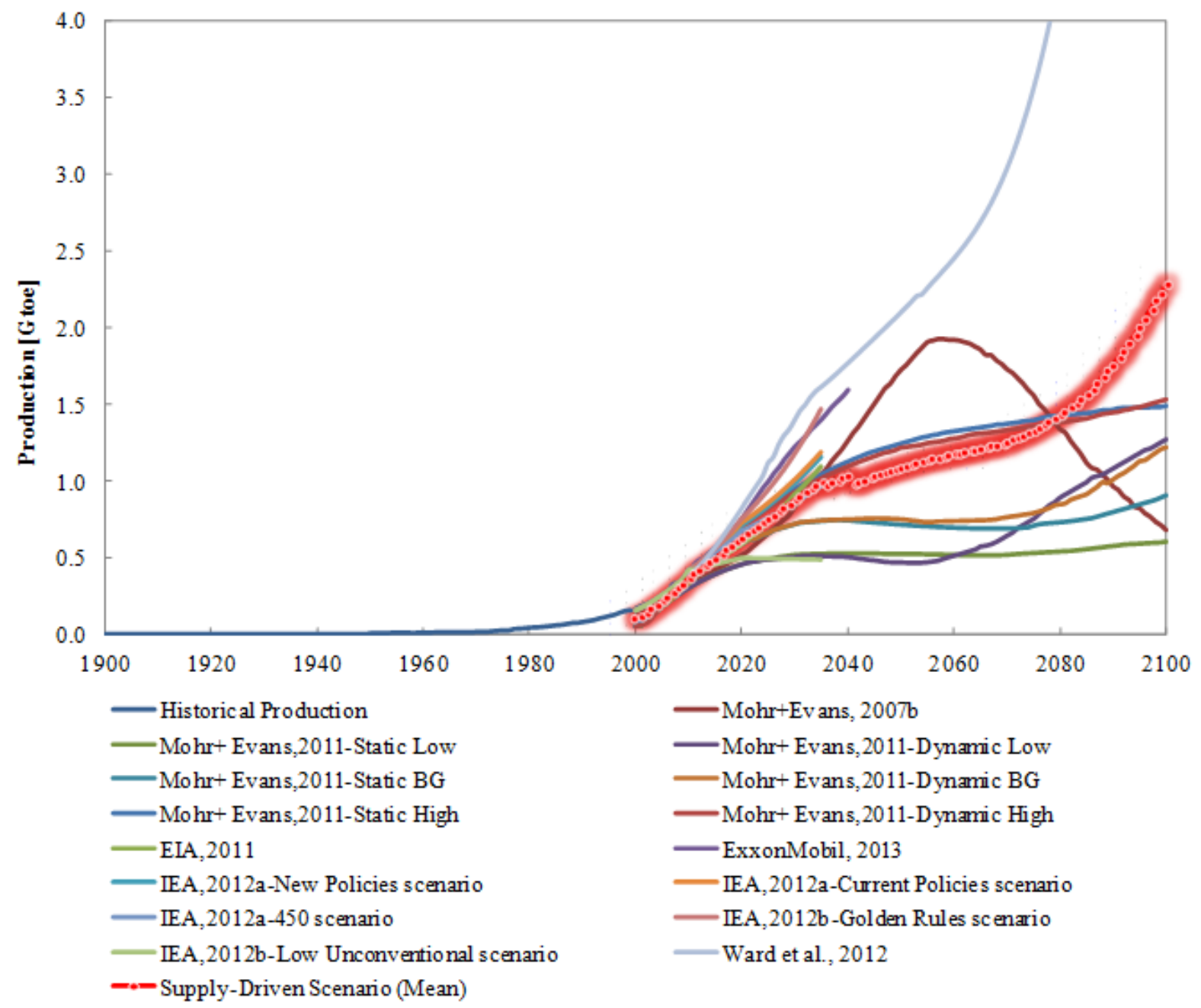

Figure A5. Fifteen long-term production scenarios for the annual production of world unconventional gas, drawn from peer-reviewed literature and mainstream energy institutes' reports published since the year 2000. Note: the very high curve is also from Ward et al.(2012). Data sources: Mohr and Evans (2007a, 2011), EIA (2011), ExxonMobil (2013), IEA (2012a,2012b), Ward et al. (2012). 